\title{
Asthma education: an essential component in asthma management
}

\author{
Louis-Philippe Boulet
}

Affiliation: Institut universitaire de cardiologie et de pneumologie de Québec, Université Laval, Québec, QC, Canada.

Correspondence: Louis-Philippe Boulet, Institut universitaire de cardiologie et de pneumologie de Québec, 2725 Chemin Sainte-Foy, Québec, QC, Canada G1V 4G5. E-mail: Ipboulet@med.ulaval.ca

-

@ERSpublications

Targeted simple educational interventions including key messages to the patient can help reduce asthma burden http://ow.ly/RW16D

Despite recent developments in our understanding of what could be the optimal management of asthma and renewed efforts from guidelines developers to help clinicians integrate their recommendations into current care, asthma remains a major human and economic burden [1-3]. Asthma is a variable condition, which unfortunately often remains uncontrolled, resulting in frequent acute healthcare use and impaired quality of life. Patient involvement in the management of their condition helps improve its control, and most patients agree to play such a role $[4,5]$. However, to be able to manage asthma adequately, those suffering from asthma should understand the nature of the disease, how to assess its control, the basic principles of treatment and the peculiarities associated with their own case, in addition to learning essential self-management skills $[4,6,7]$. Self-management asthma education is therefore considered by current asthma guidelines and strategies to be an essential component in the management of asthma, and is recommended with the highest level of evidence [8-10].

Previously reported asthma educational programmes provided variable effects, probably due to differences in the content, methods, training of educators and the ability of the latter to influence patient behaviour, patient motivation, inclusion of shared-decision strategies and patient educational, psychosocial and economical background $[4,6,11]$. Nevertheless, the bulk of evidence shows that when quality interventions are offered, self-management education results in an improvement in adherence to therapy and in most asthma outcomes $[4,6,12-14]$.

Unfortunately, self-management asthma education is still insufficiently provided [3,15-17]. This can be explained by many factors, including patient-related barriers to participation in such programmes, physicians' non-integration of asthma education into current practice, and/or structural and organisational problems.

First, patients are sometimes reluctant to attend educational programmes, even when available at no or minimal cost [18]. This may be due to a lack of time and/or motivation, difficulty accessing this service, or simply a perception that they do not need this intervention. They might not want to participate in decision-making if they feel they lack sufficient knowledge or experience to do so $[5,19,20]$. Secondly, in many instances, physicians might not have, as is often reported, the time, skills, motivation, perception of the need, or resources to provide formal asthma education, particularly in primary care settings [21, 22]. As an example, Weiner-OGilvie et al. [21] performed a survey of 15 general practices in Scotland (UK) considering the key recommendations of asthma guidelines. With regard to the recommendation to offer self-management education, including written asthma action plans focussing on individual needs, to all patients with asthma, particularly those admitted to hospital, $98.4 \%$ of physicians were aware of this recommendation and $79.7 \%$ believed that its implementation would improve asthma management;

Received: Aug 62015 | Accepted: Aug 72015

Conflict of interest: None declared.

Copyright OERS 2015 
however, almost half mentioned the need to re-organise asthma care to improve its implementation while only $12.8 \%$ of general practitioners provided an action plan to their patients. So, even if patients and physicians believe in the need for asthma education, limitations in time and resources, as well as organisational problems, may affect its delivery. A lack of available trained educators to whom the physician can refer asthma patients may also be part of the problem [22, 23].

There is therefore a need to help increase access to asthma education and facilitate its administration. Physicians are considered the best to persuade patients about the need to improve their knowledge and skills, while motivational interviews, easy access to trained educators and peer influence can address patients' barriers to participation in educational programmes. Furthermore, various means to help clinicians consider and promote education to patients, such as paper, stamps or electronic reminders of current recommendations, and availability of educators at the site of practice, can improve the delivery of those interventions [24-26]. In one of our recent reports, offering educational services through an experienced educator who attended family medicine clinics resulted in a significant reduction in unscheduled physician visits and more appropriate medication use, as well as increased provision of an action plan [25]. Furthermore, an emergency department-based "automatic" referral programme to an asthma educator resulted in improved assessment of asthma control and a marked increase in such referral [18].

In this issue of the European Respiratory Journal, PLAZA et al. [27] present a 1-year cluster randomised controlled multicentre study of 230 adults with mild-to-moderate persistent uncontrolled asthma, which assesses the effects of an asthma educational programme based on a repeated short intervention (AEP-RSI) on asthma control and quality of life. The intervention consisted of four face-to-face sessions at 3-month intervals, plus administration of a personalised, simplified written action plan and inhaler technique training. There were two control groups: one that included standard practice, and another that included the gold standard asthma education programme. Educational messages were provided by physicians, educators and/or nurses, all of whom had received specific training to make the messages uniform. The mean time for implementation of the short educational programme $(10.7 \mathrm{~min}$ for the initial visit and $6.4 \mathrm{~min}$ for the subsequent follow-up visits) is surprisingly short. The benefit of this short encounter could, however, depend on the type of information provided, the communication skills of the health professional and the ability of each individual to learn and integrate the notions provided. Nevertheless, in the study, there was a significant improvement in the asthma control score in the three groups, although it was more marked in the short intervention and gold standard groups compared with usual practice. The two types of educational interventions also resulted in reduced exacerbations and greater increases in quality of life. The authors suggest that the AEP-RSI is another effective way of improving asthma outcomes.

Simpler educational interventions have previously been proposed but many have failed to improve asthma control, although most could reduce exacerbations [28-30]. The study by PLAZA et al. [27] suggests that "simplified" educational interventions can be effective if they offer the essential elements of an effective educational intervention, such as key information on asthma management, provision of a personalised but easy to understand action plan, and inhaler technique training $[4,8,31,32]$. The study's success may also be partly explained by the repetition of key messages at regular intervals over a 1-year period, the three components of the education programme being checked at each encounter, and the establishment of individualised goals for each patient [32].

This study adds to the evidence that targeted educational programmes providing key messages on asthma management are useful in reducing untoward asthma consequences, even if asthma is mild to moderate, as shown in a previous study [25]. It confirms that gold standard educational programmes are highly effective but that shorter, simpler, well-designed programmes may also work. Hopefully, this can motivate delivery of such interventions to patients, particularly when resources are limited. However, both the quality of the programme and the training of educators and consistency of messages should be ensured. Programmes should be based on sound theories of education and behavioural changes [33].

In conclusion, initiatives that allow effective educational interventions to be more easily integrated into current care are welcome. This will hopefully help improve long-term outcomes for a disease that can be controlled in the vast majority of patients. Asthma therapy should further improve over time but simple interventions can already make a major difference.

\section{References}

1 Fitzgerald JM, Boulet LP, Mcivor RA, et al. Asthma control in Canada remains suboptimal: The Reality of Asthma Control (TRAC) study. Can Respir J 2006; 13: 253-259.

2 Soriano JB, Rabe KF, Vermeire PA. Predictors of poor asthma control in European adults. J Asthma 2003; 40: 803-813.

3 Nathan RA, Thompson PJ, Price D, et al. Taking aim at asthma around the world: global results of the Asthma Insight and Management Survey in the Asia-Pacific region, Latin America, Europe, Canada, and the United States. J Allergy Clin Immunol Pract 2015; 3: 734-742. 
Gibson PG, Powell H, Coughlan J, et al. Self-management education and regular practitioner review for adults with asthma. Cochrane Database Syst Rev 2003; 1: CD001117.

5 Caress $\mathrm{AL}$, Beaver $\mathrm{K}$, Luker $\mathrm{K}$, et al. Involvement in treatment decisions: what do adults with asthma want and what do they get? Results of a cross-sectional survey. Thorax 2005; 60: 199-205.

6 Bernard-Bonnin AC, Stachenko S, Bonin D, et al. Self-management teaching programs and morbidity of pediatric asthma: a meta-analysis. J Allergy Clin Immunol 1995; 95: 34-41.

7 McDonald VM, Gibson PG. Asthma self-management education. Chron Respir Dis 2006; 3: 29-37.

8 Global Initiative for Asthma. Global Strategy for Asthma Management and Prevention. http://www.ginasthma.org/ documents/4 Date last updated: April 2015. Date last accessed: September 16, 2015.

9 British Thoracic Society, Scottish Intercollegiate Guidelines Network. British guideline on the management of asthma. Thorax 2014; 69: Suppl. 1, 1-192.

10 Lougheed MD, Lemiere C, Ducharme FM, et al. Canadian Thoracic Society 2012 guideline update: diagnosis and management of asthma in preschoolers, children and adults. Can Respir J 2012; 19: 127-164.

11 Mancuso CA, Peterson MG, Gaeta TJ, et al. A randomized controlled trial of self-management education for asthma patients in the emergency department. Ann Emerg Med 2011; 57: 603-612.

12 Côté J, Cartier A, Robichaud P, et al. Influence of asthma education on asthma severity, quality of life and environmental control. Can Respir J 2000; 7: 395-400.

13 Partridge MR, Hill SR. Enhancing care for people with asthma: the role of communication, education, training and self-management. 1998 World Asthma Meeting Education and Delivery of Care Working Group. Eur Respir J 2000; 16: 333-348.

14 Boulet L-P, Vervloet D, Magar Y, et al. Adherence: the goal to control asthma. Clin Chest Med 2012; 33: $405-417$.

15 Boulet LP, Devlin H, O’Donnell DE. The Physicians' Practice Assessment Questionnaire on asthma and COPD. Respir Med 2011; 105: 8-14.

16 Boulet LP, Bourbeau J, Skomro R, et al. Major care gaps in asthma, sleep and chronic obstructive pulmonary disease: a road map for knowledge translation. Can Respir J 2013; 20: 265-269.

17 Holgate ST, Price D, Valovirta E. Asthma out of control? A structured review of recent patient surveys. BMC Pulm Med 2006; 6: Suppl. 1, S2.

18 Robichaud P, Laberge A, Allen MF, et al. Evaluation of a program aimed at increasing referrals for asthma education of patients consulting at the emergency department for acute asthma. Chest 2004; 126: 1495-1501.

19 Guadagnoli E, Ward P. Patient participation in decision-making. Soc Sci Med 1998; 47: 329-339.

20 Caress A-L, Luker KA, Woodcock AA, et al. A qualitative exploration of treatment decision-making role preference in adult asthma patients. Health Expect 2002; 5: 223-225.

21 Wiener-Ogilvie S, Pinnock H, Huby G, et al. Do practices comply with key recommendations of the British Asthma Guideline? If not, why not? Primary Care Respir J 2007; 16: 369-377.

22 Canonica GW, Baena-Cagnani CE, Blaiss MS, et al. Unmet needs in asthma: Global Asthma Physician and Patient (GAPP) Survey: global adult findings. Allergy 2007; 62: 668-674.

23 Cowie RL, Cicutto L, Boulet LP, et al. Asthma education and management programs in Canada. Can Respir J 2001; 8: 416-420.

24 Renzi PM, Ghezzo H, Goulet S, et al. Paper stamp checklist tool enhances asthma guidelines knowledge and implementation by primary care physicians. Can Respir J 2006; 13: 193-197.

25 Boulet LP, Boulay MÈ, Gauthier G, et al. Benefits of an asthma education program provided at primary care sites on asthma outcomes. Respir Med 2015; 109: 991-1000.

26 Lougheed MD, Minard J, Dworkin S, et al. Pan-Canadian REspiratory STandards INitiative for Electronic Health Records (PRESTINE): 2011 national forum proceedings. Can Respir J 2012; 19: 117-126.

27 Plaza V, Peiró M, Torrejón M, et al. A repeated short educational intervention improves asthma control and quality of life. Eur Respir J 2015; 46: 1298-1307.

28 Dalcin PT, Grutcki DM, Laporte PP, et al. Impact of a short-term educational intervention on adherence to asthma treatment and on asthma control. J Bras Pneumol 2011; 37: 19-27.

29 Morell F, Ojanguren I, Cordovilla R, et al. Two short interventions to reduce health care requirements in asthma patients. A multicentre controlled study (ASTHMACAP II). Med Clinica 2014; 142: 348-354.

30 Côté J, Bowie DM, Robichaud P, et al. Evaluation of two different educational interventions for adult patients consulting with an acute asthma exacerbation. Am J Respir Crit Care Med 2001; 163: 1415-1419.

31 Gardner A, Kaplan B, Brown W, et al. National standards for asthma self-management education. Ann Allergy Asthma Immunol 2015; 114: 178-186.

32 Kolbe J. Asthma education, action plans, psychosocial issues and adherence. Can Respir J 1999; 6: 273-280.

33 Green LW, Kreuter MW. Health Promotion Planning: an Educational and Environmental Approach. 2nd Edition. California, Mayfield Publishing Company, 1991. 